\title{
28 Research Soure \\ Performance Analysis of Optical AND Gate Using T- Shaped Waveguide
}

Dalai Gowri sankar Rao ( $\nabla$ dgsrao26@gmail.com )

Godavari Institute of Engineering and Technology https://orcid.org/0000-0003-1770-6731

Seeta Rama Raju Karyabhattu

Godavari Institute of Engineering and Technology

Sandip Swarnakar

G Pullaiah College of Engineering and Technology

Santosh Kumar

DIT University

\section{Research Article}

Keywords: all-optical AND gate, photonic crystals, beam-interference, transmission ratio, response time

Posted Date: April 29th, 2021

DOI: https://doi.org/10.21203/rs.3.rs-432288/v1

License: (c) (1) This work is licensed under a Creative Commons Attribution 4.0 International License. Read Full License 


\section{Abstract}

Ultra-compact all-optical AND logic gate is realized for optical processing and photonic integrated devices with two-dimensional photonic crystal waveguides based on beam interference principle. The performance of the structure is examined and evaluated by optimized parameters such as refractive index and silicon rod radius. The results obtained from a numerical calculation using the finite-difference time-domain (FDTD) method and plane wave expansion method. The photonic crystal based all-optical AND logic gate has benefits of compact size as $38.88 \mu m 2$, operated at low power levels, high transmission ratio and good time response as $0.124 \mathrm{ps}$. Associated with conventional semiconductor optical amplifiers, Mach-Zehnder interferometer and photonic crystal ring resonators proposed methodology provides better performance with a high achieved more than $97 \%$ transmission ratio, at a wavelength of $1.55 \mu \mathrm{m}$.

\section{Full-text}

Due to technical limitations, full-text HTML conversion of this manuscript could not be completed. However, the manuscript can be downloaded and accessed as a PDF.

\section{Tables}

Due to technical limitations, table 1 is only available as a download in the Supplemental Files section.

Table 2. All-optical AND logic gate for different RI values with normalized input and output power values

\begin{tabular}{|llllll|}
\hline \multirow{2}{*}{ Input } & \multicolumn{4}{l|}{ Output Power } \\
\cline { 2 - 6 } & \multicolumn{5}{c|}{ Refractive Index Variations } \\
\hline A & B & 3.42 & 3.44 & 3.46 & 3.48 \\
\hline 0 & 0 & 0.02 & 0.042 & 0.024 & 0.032 \\
\hline 0 & 1 & 0.14 & 0.12 & 0.088 & 0.03 \\
\hline 1 & 0 & 0.010 & 0.017 & 0.012 & 0.021 \\
\hline 1 & 1 & 0.75 & 0.75 & 0.731 & 0.671 \\
\hline
\end{tabular}

Table 3. All-optical AND logic gate for different silicon rod radius values with normalized input and output power values while optimized RI of 3.42 


\begin{tabular}{|llllll|}
\hline \multirow{2}{*}{ Input } & \multicolumn{4}{l|}{ Output Power } \\
\cline { 3 - 6 } & \multicolumn{5}{l|}{ Silicon rod radius values } \\
\hline A & B & $0.16 a$ & $0.18 \mathrm{a}$ & $0.2 \mathrm{a}$ & $0.22 \mathrm{a}$ \\
\hline 0 & 0 & 0.08 & 0.05 & 0.02 & 0.04 \\
\hline 0 & 1 & 0.18 & 0.21 & 0.14 & 0.16 \\
\hline 1 & 0 & 0.017 & 0.015 & 0.010 & 0.02 \\
\hline 1 & 1 & 0.7 & 0.72 & 0.75 & 0.65 \\
\hline
\end{tabular}

Table 4. Comparison of proposed design with earlier designs in terms of various parameters

\begin{tabular}{|lllll|}
\hline Dimensions & Contrast ratio & Transmission ratio & Response time & Ref \\
\hline $9.45 \times 13.5 \mu$ & $6.7 \mathrm{~dB}$ & - & - & 16 \\
\hline $9 \times 9 \mu$ & $6.017 \mathrm{~dB}$ & - & $0.63 \mathrm{ps}$ & 22 \\
\hline $8.64 \times 5.64 \mu$ & $19.46 \mathrm{~dB}$ & - & $0.15 \mathrm{ps}$ & 23 \\
\hline $8.1 \times 12.5 \mu$ & - & $92 \%$ & - & 26 \\
\hline $7.2 \times 5.4 \mu$ & $18.7 \mathrm{~dB}$ & $97 \%$ & $0.124 \mathrm{ps}$ & Proposed \\
\hline
\end{tabular}

Figures 


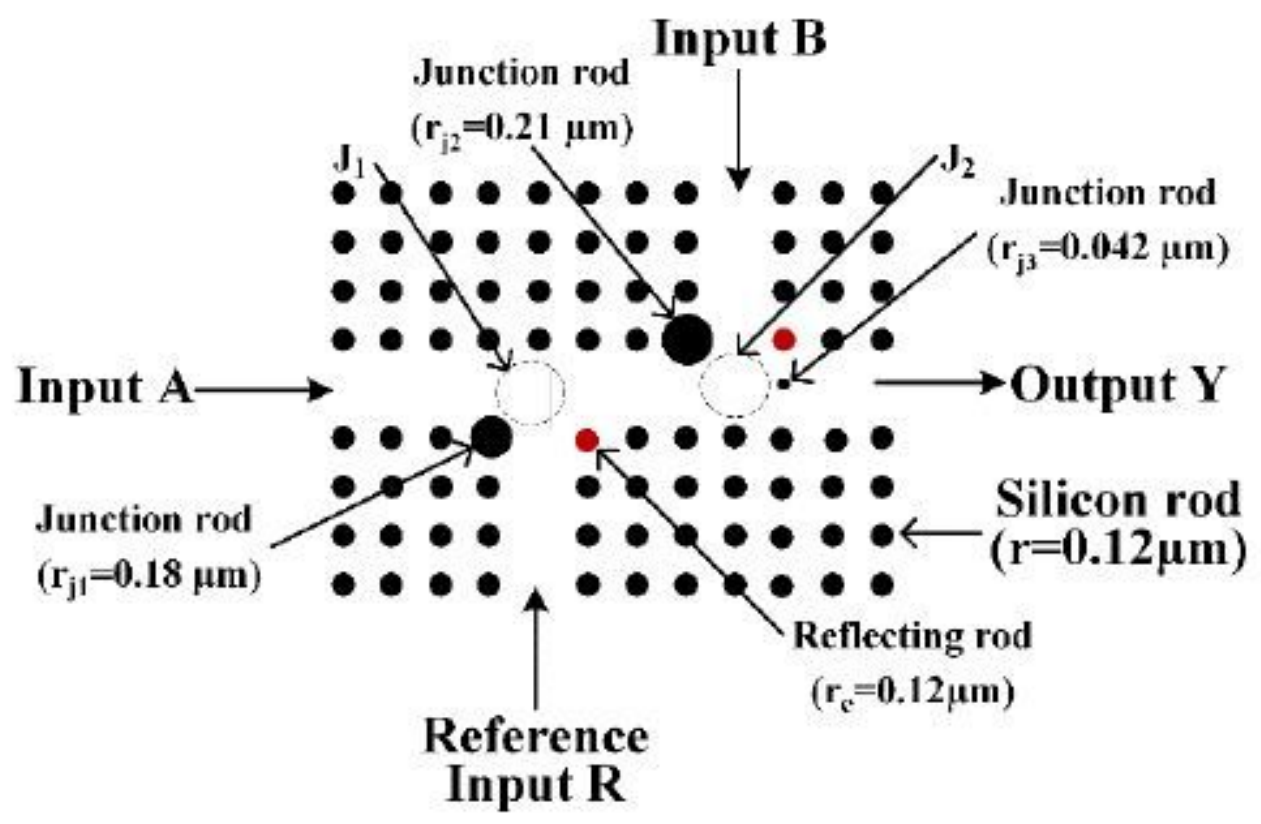

Figure 1

Diagram of all-optical AND logic gate with two T-shaped photonic crystals

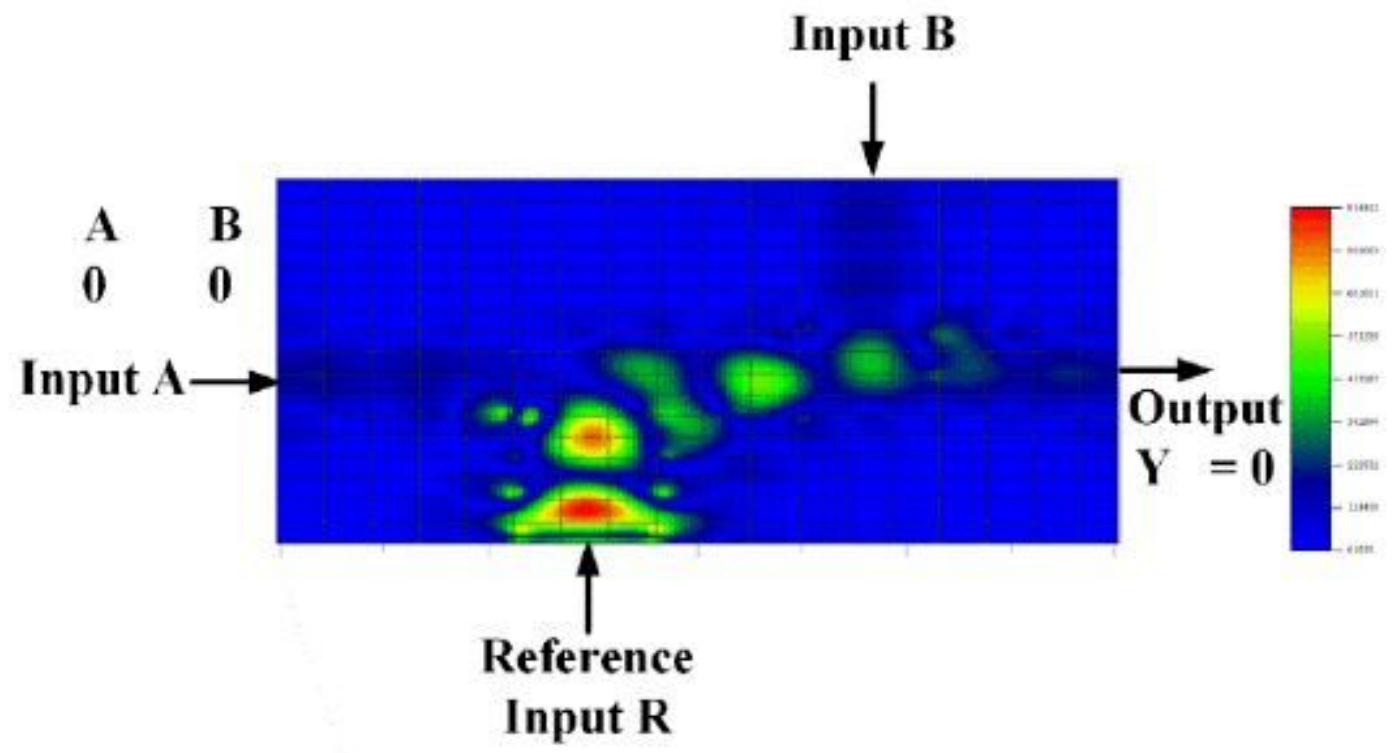

Figure 2

Light propagation for input condition $A$ and $B$ is ' 0 ' 


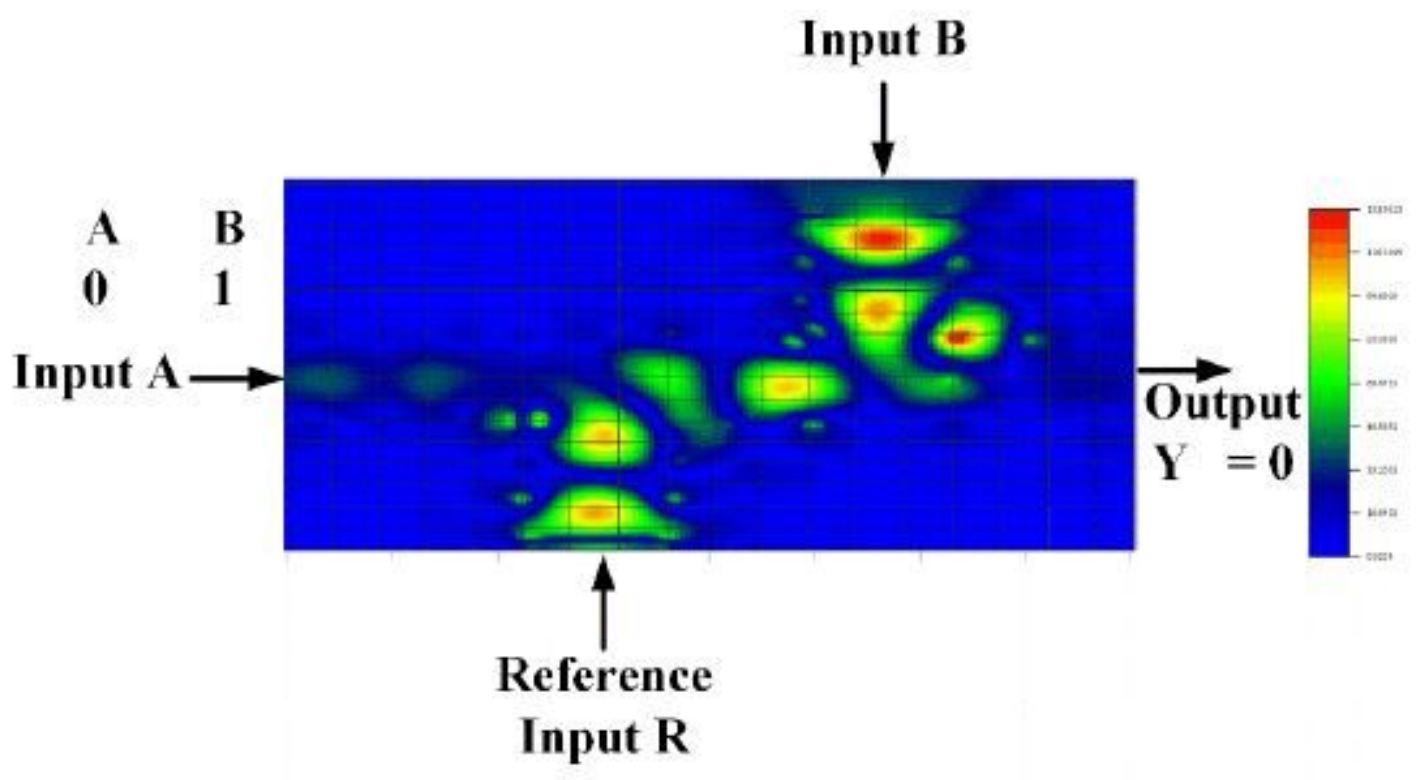

Figure 3

Light propagation for input condition $A$ is ' 0 ' and $B$ is ' 1 '

Input B

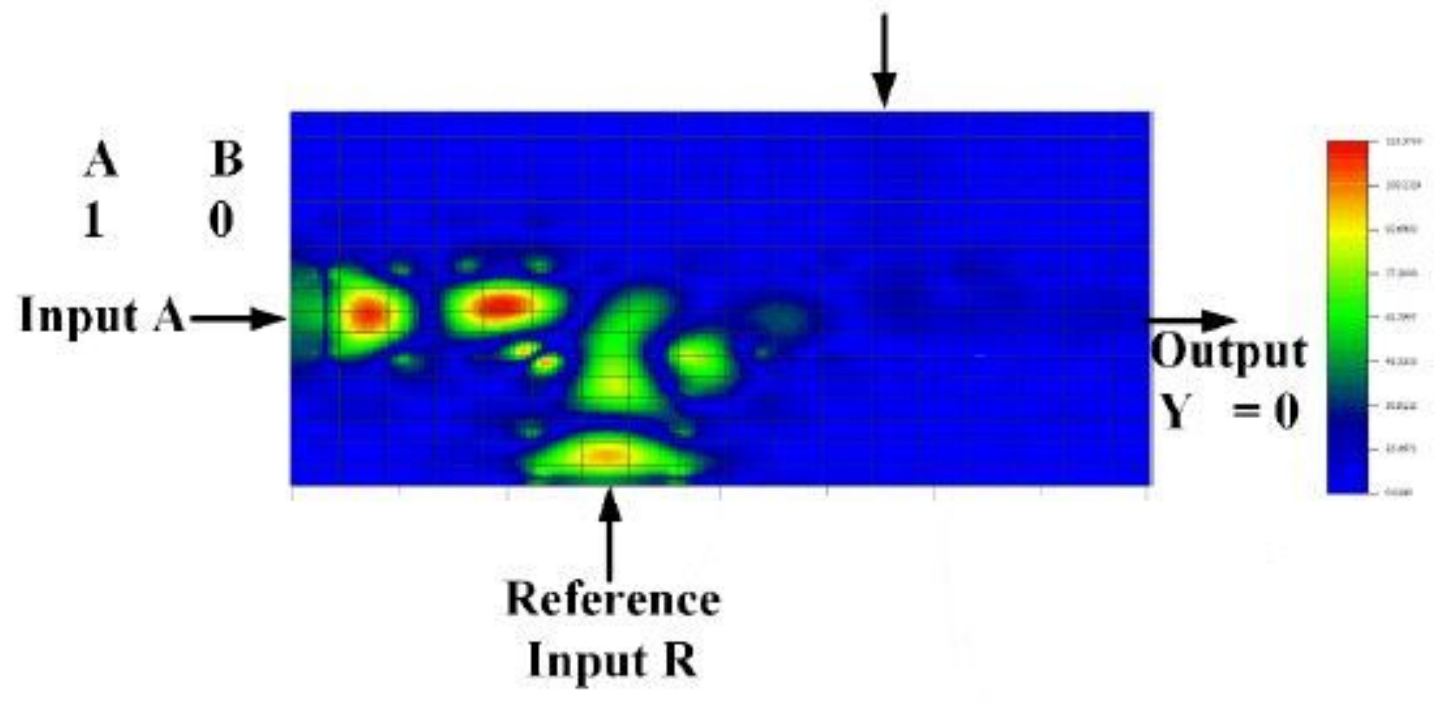

Figure 4

Light propagation for input condition $A$ is ' 1 ' and $B$ is ' 0 ' 


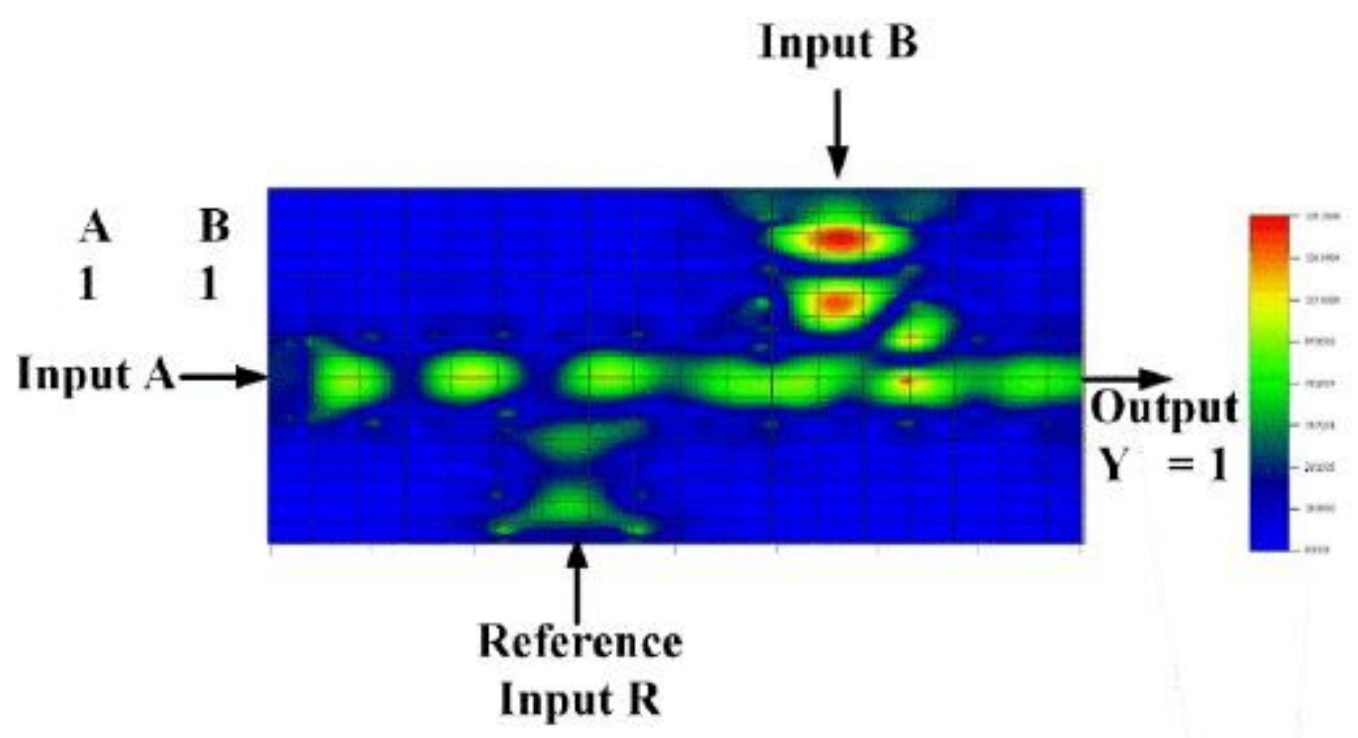

Figure 5

Light propagation for input condition $A=1$ and $B=1$

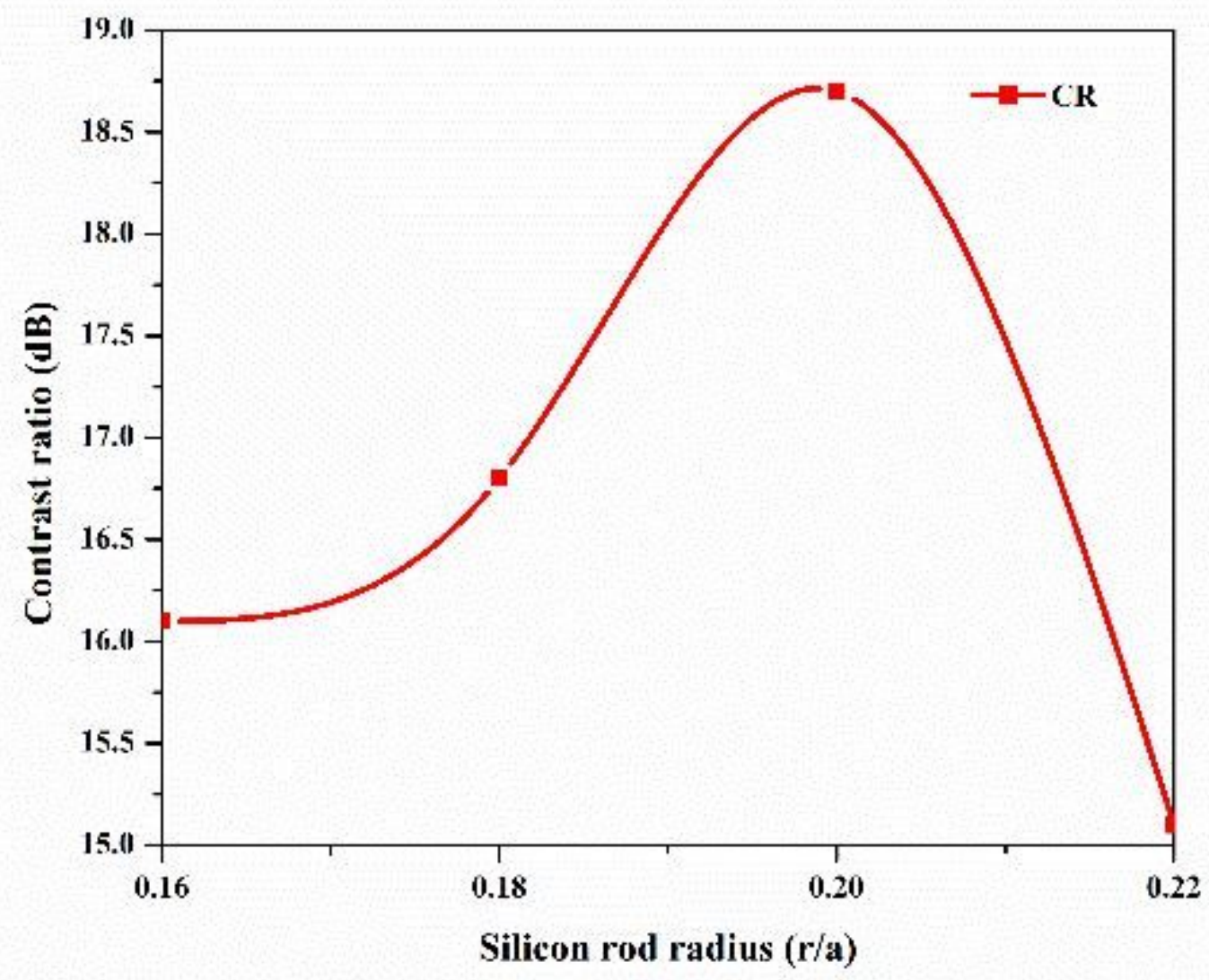

Figure 6 
Contrast ratio of all-optical AND logic gate for different (a) refractive index

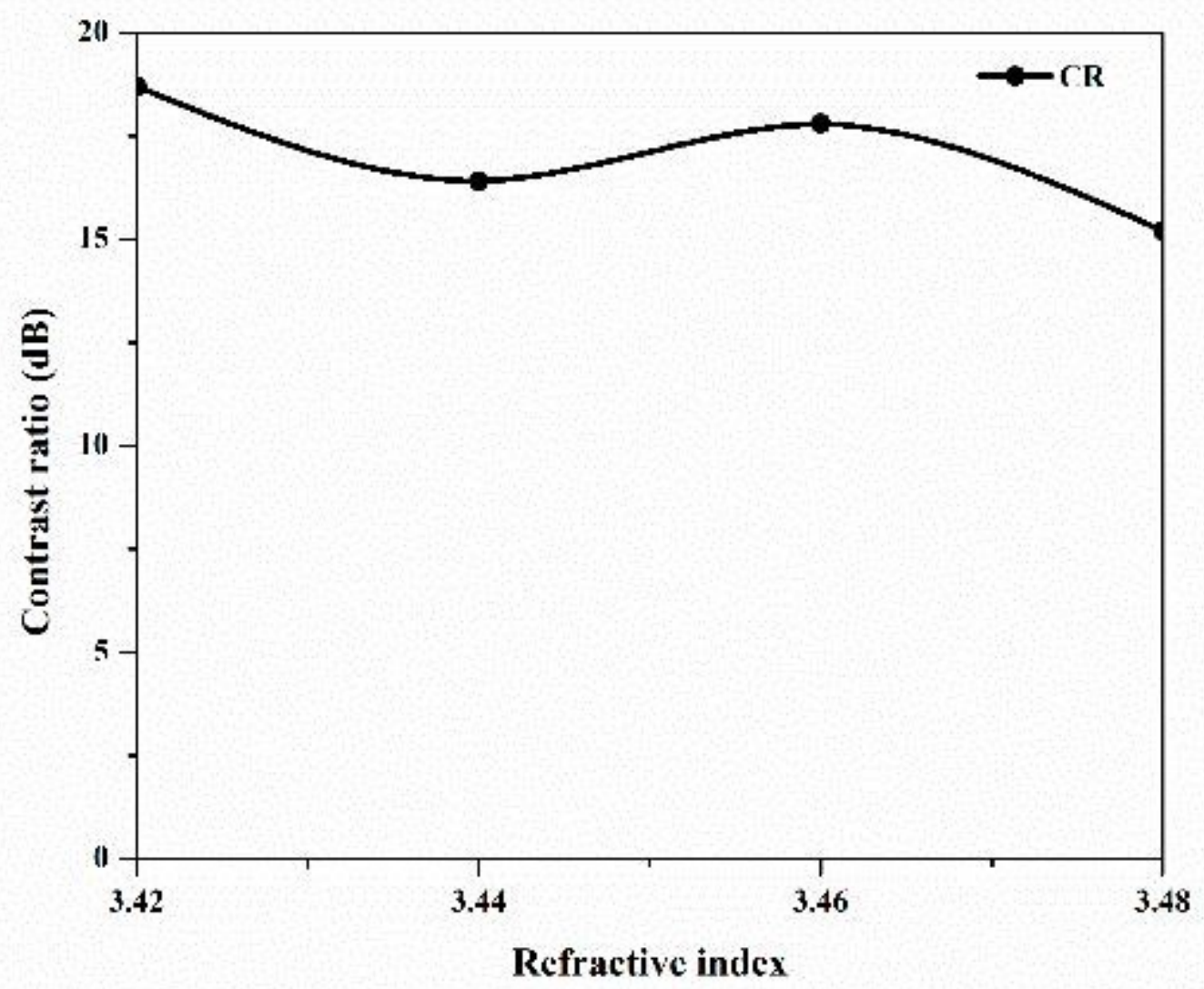

Figure 7

Contrast ratio of all-optical AND logic gate for different (a) silicon rod radius 


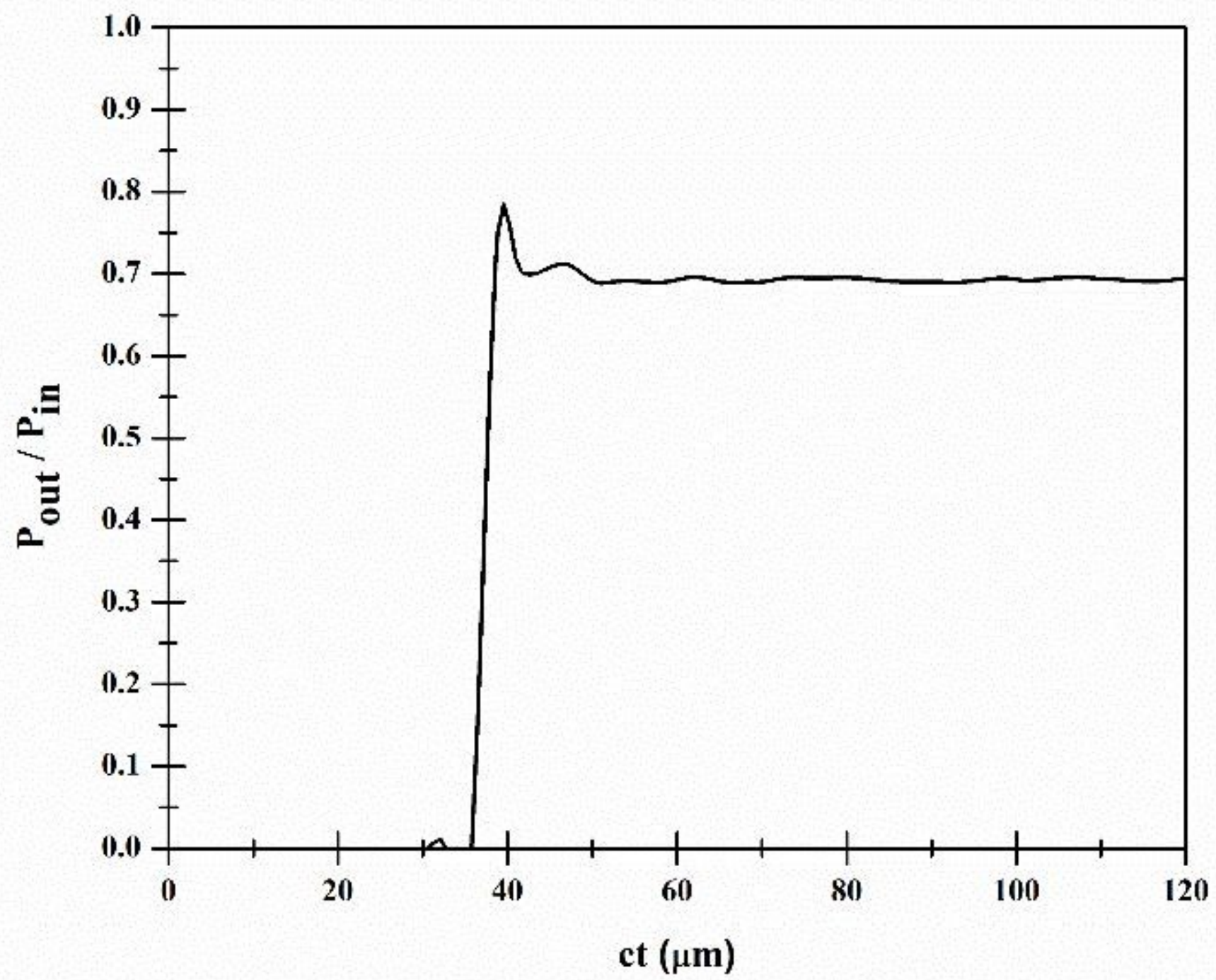

Figure 8

Time response curve of the output power for input condition '11'

\section{Supplementary Files}

This is a list of supplementary files associated with this preprint. Click to download.

- Table1.docx 